\title{
Interactive Videos vs. Hypertext Documents - The Effect on Learning Quality and Time Effort when Acquiring Procedural Knowledge
}

\author{
Alexander Keller \\ University of Passau \\ alexander.keller@uni-passau.de
}

\author{
Michael Langbauer \\ University of Passau \\ michaellangbauer@gmail.com
}

\author{
Thomas Fritsch \\ University of Passau \\ fritsc19@gw.uni-passau.de
}

\author{
Franz Lehner \\ University of Passau \\ franz.lehner@uni-passau.de
}

\begin{abstract}
The use of information systems and the rise of new learning concepts have changed the way individuals are acquiring knowledge in organizational, educational and private contexts. Recently, video tutorials have become a widely-used instrument for learning and successful platforms emerged, offering massive open online courses based on video content. With the existence of different learning technologies the question arises: How these media formats affect the learning performance of individuals? We introduce interactive videos as a new media format and compare this technology to hypertext documents in an educational context. Our results from an experiment with 130 participants reveal that the learning quality can be significantly increased when interactive videos are used to acquire procedural knowledge. However, we did not observe any effect on time effort.
\end{abstract}

\section{Introduction}

In educational, organizational as well as private contexts, acquiring knowledge is strongly influenced by the use of technology. Information systems (IS) and information technologies (IT) change the way how knowledge is consumed by providing access to high quality and standardized learning content across institutional boundaries [1]. Recently, this shift has lead to a strong emergence of new teaching concepts like massive open online courses (MOOCs) on platforms like EdX, Udacity, and Coursera. These large-scale courses are held by experts who facilitate a series of video lectures in an open access format via the web [2]. Besides MOOCs, YouTube represents a powerful platform to acquire knowledge from user generated video content. Google states that nearly $70 \%$ of search requests on YouTube in 2015 included the term "how to", which represents the large amount of users in search of information provided via video tutorials [3]. Apart from videos on how to solve a specific task (e.g. running an upgrade from Windows 7 to Windows 10), the platform also offers general learning content like concept explanations and lectures. Although a large amount of information is available in form of videos (i.e. auditory verbal information combined with visual graphical information) nowadays most of the content is still represented as simple explanatory text in hypertext documents (e.g. websites and PDF documents) or in printed media formats (e.g. books). However, as more people tend to utilize videos as a form of acquiring knowledge, the question arises whether the use of this media format affects the learning performance (i.e. learning quality, time effort) compared to the usage of hypertext documents?

Although previous work studies videos and textual representations in terms of differences and application scenarios, it often lacks in the comparison of media types. We argue that hypertext documents (e.g. PDF documents) include features like search and link functionalities, that are not offered in videos. To navigate and identify relevant parts in videos one has to fastforward and rewind. Therefore, hypertext documents and videos are not comparable as conditions in experiments. We try to overcome this problem by introducing interactive videos as media format that includes those features (e.g. searching and linking). This technology embraces the hypermedia structure of internet applications to create a non-linear graph of video scenes which is supplemented with additional information and interaction elements [4]. With using interactive videos as treatment and hypertext documents as control condition we ensure the comparability of experiment conditions. Based on 130 participants, we study the treatment's effect on learning performance. As a result, we observe a significant positive effect on the learning quality and user perception when using an interactive video. We thereby contribute to research in two ways: First we bridge the research gap identified by Strecker et al. (2018), who state that "no specific measurement instrument exists that measures the learning performance or other benefits from interactive videos" [5]. Second, we 
clarify the effect observed from prior work studying the application of interactive videos in an educational context.

The rest of the paper is structured as follows: First, we relate our work to prior studies and explain the theoretical background to clarify our contribution. Second, we outline the applied research design and describe the conditions (i.e. interactive video tutorial and PDF manual) in the experiment. Third, we present our empirical investigation and discuss the results in regard to our research question. Finally, we give managerial implications and outline future research.

\section{Related Work}

Prior work in the field of technology enhanced learning falls into three different categories: i) studies focusing on psychological aspects of learning with media in general, ii) studies investigating the learning achievements or performance of different media types and iii) studies recommending the use of certain media formats. The first category builds the theoretical foundation of our contribution and investigates the positive effect of videos on learning. For studies in the second and third category a systematic literature review is performed to identify related work and to specify the research gap.

The first category is strongly related to the dualcoding theory of Allan Paivio (1971) which postulates that learning performance can be increased when verbal associations and visual imagery is combined in learning artifacts [6]. Related to this theory Baddeley and Hitch (1974) propose the model of working memory which is used by Sweller (1988) to introduce the cognitive load theory $[7,8]$. This theory assumes a limited working memory of individuals which can only process a finite amount of cognitive load when performing a given task, like acquiring knowledge. Sweller (1988) describes the mental learning effort with three categories [8]: germane, intrinsic and extraneous cognitive load. The theory indicates that the learning performance can be increased by reducing these loads, for example, by an adjustment of the presentation format. Based on this idea, several media design schemes have been developed to enhance the learning performance: The modality principle states that users learn better from graphics and audio narration than animation and text [9]. Therefore, the learning of complex tasks can be increased by presenting information as speech rather than on-screen text $[10,11]$. This is accompanied by the coherence principle which focuses on the reduction of extraneous cognitive load by avoiding unnecessary and irrelevant content
$[12,13,14,15]$. Therefore, the emphasis should lay on presenting relevant content by mixing audio narration with visual animations to reduce germane load instead of using extraneous details [16]. Intrinsic load can be decreased with the segmentation principle by dividing complex information and content into smaller pieces to give individuals control over the learning pace [17, 18]. To ensure the quality of media formats, we build on these principles and findings to design the conditions in our experiment. First, we implement the modality principle in the interactive video presented to the participants by combining audio and visual information. Second, segmentation is considered in providing a linked table of content and search functionality within the interactive video and the PDF manual. Third, we are taking into account the coherence principle by creating the interactive video tutorial and a PDF manual with a strong focus on the task the participants have to solve. ${ }^{1}$

Besides the psychological aspects of learning, studies in the second category are investigating the learning achievements of different media formats. Most of these studies use performance as measurement for the learning outcome. However, performance can be investigated in various forms. While some authors apply quality aspects, like the results in an exam or test $[19,20]$, others use efficiency measures, like time effort for learning $[21,22]$, as a proxy of learning performance.

In the third category, literature favors specific media types for learning. The application of videos in learning scenarios is broadly discussed and doubts are brought forward regarding their effectiveness compared to print mediums [19, 23, 24, 25]. In contrast to Choi and Yang (2011), Beitzel and Derry (2009) state that videos do not necessarily improve learning and recommend the use of textual representations like books [26, 27]. Besides that, certain formats are preferred in specific scenarios. In a search task where the underlying problem has to be identified before solving the task, textual representations can be more effective than videos. This is due to the linear structure, because videos cannot be visually screened for relevant information like texts. Table 1 on the next page gives an overview of selected prior work studying the learning performance with different media types.

In summary, we draw several conclusions: First, in prior work the effects of video versus text are studied regarding the learning performance with a strong focus on educational scenarios. However, the underlying definitions and evaluations of learning performance differ which could be one reason for the divergent findings. Second, most of the textual representations

\footnotetext{
${ }^{1}$ See further treatment description in section 3.1.
} 
Table 1. Prior Work Studying Learning with Different Media Formats.

\begin{tabular}{|c|c|c|c|c|c|}
\hline Source & Context & $\begin{array}{c}\text { Media } \\
\text { Types }\end{array}$ & Measures & Approach & Result \\
\hline $\begin{array}{l}\text { Ayres et } \\
\text { al. (2009) }\end{array}$ & Daily life & $\begin{array}{l}\text { Animated } \\
\text { presentation, } \\
\text { sequence of } \\
\text { diagrams }\end{array}$ & Performance & $\begin{array}{l}\text { Laboratory Experiment } \\
\qquad(1 \times 2 \text { design, } \\
\text { animation/ diagrams })\end{array}$ & $\begin{array}{l}\text { Animation results in less } \\
\text { cognitive load and better } \\
\text { learning performance. }\end{array}$ \\
\hline $\begin{array}{l}\text { Choi, } \\
\text { Johnson } \\
(2007)\end{array}$ & Education & $\begin{array}{l}\text { Video, text- } \\
\text { document }\end{array}$ & $\begin{array}{l}\text { Satisfaction, } \\
\text { Comprehen- } \\
\text { sion and } \\
\text { Retention }\end{array}$ & $\begin{array}{c}\text { Laboratory Experiment } \\
(2 \times 2 \text { design, video/text } \\
\text { with/without } \\
\text { discussion })\end{array}$ & $\begin{array}{l}\text { Without group } \\
\text { discussion, there is no } \\
\text { effect on measures. }\end{array}$ \\
\hline $\begin{array}{l}\text { Choi, } \\
\text { Yang } \\
(2011)\end{array}$ & Education & $\begin{array}{l}\text { Video, text- } \\
\text { document }\end{array}$ & $\begin{array}{l}\text { Achievement, } \\
\text { Empathy, } \\
\text { Satisfaction }\end{array}$ & $\begin{array}{l}\text { Laboratory Experiment } \\
\text { (1 x } 2 \text { design, } \\
\text { video/text })\end{array}$ & $\begin{array}{l}\text { Video is more effective } \\
\text { than text regarding the } \\
\text { three measures. }\end{array}$ \\
\hline $\begin{array}{l}\text { Hrastinski, } \\
\text { Monstad } \\
(2013)\end{array}$ & Organization & $\begin{array}{l}\text { Interactive } \\
\text { video }\end{array}$ & $\begin{array}{l}\text { Influence on } \\
\text { Behavior, } \\
\text { Satisfaction }\end{array}$ & Survey & $\begin{array}{l}\text { Negative effect on } \\
\text { behavior and positive } \\
\text { effect on satisfaction. }\end{array}$ \\
\hline $\begin{array}{l}\text { Merkt et } \\
\text { al. (2011) }\end{array}$ & Education & $\begin{array}{l}\text { Interactive } \\
\text { video, video, } \\
\text { text- } \\
\text { document }\end{array}$ & Performance & $\begin{array}{c}\text { Laboratory Experiment } \\
\text { (1 x } 3 \text { design, } \\
\text { interactive } \\
\text { video/video/text) }\end{array}$ & $\begin{array}{l}\text { Interactive video is not } \\
\text { different from text. }\end{array}$ \\
\hline $\begin{array}{l}\text { Merkt, } \\
\text { Schwan } \\
(2014)\end{array}$ & Education & $\begin{array}{l}\text { Interactive } \\
\text { video, text- } \\
\text { document }\end{array}$ & Performance & $\begin{array}{l}\text { Laboratory Experiment } \\
(1 \times 2 \text { design, } \\
\text { much/little } \\
\text { interactivity })\end{array}$ & $\begin{array}{c}\text { Interactive video results } \\
\text { in higher learning } \\
\text { performance. }\end{array}$ \\
\hline $\begin{array}{l}\text { Schwan, } \\
\text { Riempp } \\
(2004)\end{array}$ & Daily life & $\begin{array}{l}\text { Interactive } \\
\text { video }\end{array}$ & Performance & Laboratory Experiment & $\begin{array}{l}\text { More interactivity in } \\
\text { videos leads to a better } \\
\text { learning performance. }\end{array}$ \\
\hline $\begin{array}{l}\text { Stice et } \\
\text { al. }(2016)\end{array}$ & Education & $\begin{array}{l}\text { Video, text- } \\
\text { document }\end{array}$ & Performance & Online Learning Tool & $\begin{array}{c}\text { Studying with text } \\
\text { materials leads to higher } \\
\text { exam scores than } \\
\text { studying with videos. }\end{array}$ \\
\hline $\begin{array}{l}\text { This } \\
\text { study }\end{array}$ & Education & $\begin{array}{l}\text { Interactive } \\
\text { video, } P D F \\
\text { manual }\end{array}$ & $\begin{array}{l}\text { Learning } \\
\text { Quality, Time } \\
\text { Effort, User } \\
\text { Perception }\end{array}$ & $\begin{array}{l}\text { Laboratory Experiment } \\
\left(\begin{array}{l}1 \times 2 \text { design, video/ } \\
\text { text) and questionnaire }\end{array}\right.\end{array}$ & $\begin{array}{l}\text { Interactive Videos have } \\
\text { a positive effect on } \\
\text { learning quality and no } \\
\text { effect on time effort. }\end{array}$ \\
\hline
\end{tabular}

used in experiments are in formats (e.g. print, video, hypertext), which are not fully comparable regarding their functionalities (e.g. linked content, search). This could result in a bias that is related to the design of the presented media formats.

\section{Research Design}

With this study, we investigate and compare the learning performance of interactive videos and hyptertext documents in an educational scenario. Due to the different perspectives on learning performance, we focus on learning quality (LQ) and time effort (TE). With this we built upon prior work from Blickle (1996) [28].
We conduct a laboratory experiment with a 1x2 between-subjects design and use a hypertext document in form of a PDF manual and an interactive video tutorial as conditions. In the experiment, the participants are asked to create a hypervideo ${ }^{2}$ using the software tool SIVA Suite.

Based on the treatment they are presented with an interactive video tutorial or a PDF manual as well as a description of the task including different scenes, sequence order and loops. The participants are instructed to solve the task with SIVA Suite and use the PDF manual or the interactive video tutorial as information on how to use the tool. As SIVA Suite has recently been developed at

\footnotetext{
${ }^{2}$ A hypervideo is an interactive video. In the study this term is used for the result of the task the participants have to solve.
} 
the university the participants are not familiar with the tool. We decide to use a student sample to ensure that participants are used to new technologies and are in contact with learning scenarios in their everyday live.

Furthermore, we use a questionnaire at the end of the experiment to evaluate users' perceptions when using a PDF manual versus interactive video tutorial. The questions are derived by commonly applied measures of utilization models from IS research and related fields (see table 3).

\subsection{Experimental Treatment and Visualization}

The control condition in our experiment is a hypertext document in form of a PDF manual presented via Adobe Acrobat Reader. This manual describes SIVA Suite's functionalities with textual information and screenshots. Additionally it provides linked table of contents and search functionality. As treatment, we use an interactive video tutorial in which SIVA Suite's different functionalities are shown in a screencast and explained verbally by a person. Interactive elements within the interactive video are available in form of a table of contents and a search field.

These features should support the user in navigating through the different sections of the PDF manual or interactive video tutorial. Besides fill words and connecting sentences in the audio track of the interactive video tutorial, the content of both formats is identical. This ensures the comparability between the two conditions. The only difference is the presentation format, making them solid conditions in our experimental setting.

\section{Empirical Analysis}

\subsection{Measures}

We evaluate the learning performance of an interactive video versus a PDF manual in a scenario where people acquire procedural knowledge to solve a specific task. To evaluate the learning performance, we introduce the measures learning quality $(L Q)$ and time effort (TE). $L Q$ is representing the accordance of the created results with the requirements defined in the task description. This measure is based on the taxonomy of educational objectives by Bloom (1956), which is broken into six levels of objectives [29]: knowledge, comprehension, application, analysis, synthesis, evaluation. Each aspect represents a level of $L Q$ and is related to a specific subtask. The tasks are built upon each other and each is related to a specific learning quality level. We apply these objectives on our experimental setting and define adequate requirements to examine and assign the participants' results to one of the learning quality levels, see table 2 .

Table 2. Learning Quality Levels.

\begin{tabular}{|c|c|c|}
\hline Objective & Subtask & Level \\
\hline Evaluation & $\begin{array}{l}\text { Video supports complete } \\
\text { functionality required } \\
\text { by the task description. } \\
\text { Evaluation of the gen- } \\
\text { erated results based on } \\
\text { task description. }\end{array}$ & 0 \\
\hline Synthesis & $\begin{array}{l}\text { Adding a global anno- } \\
\text { tation. Construction of } \\
\text { a new element based on } \\
\text { synthesizing given infor- } \\
\text { mation without instruc- } \\
\text { tion. }\end{array}$ & 1 \\
\hline Analysis & $\begin{array}{l}\text { Annotation of scenes and } \\
\text { creation of loops. Anal- } \\
\text { ysis of the given graph } \\
\text { and reorganization with } \\
\text { additional notation ele- } \\
\text { ments. }\end{array}$ & 2 \\
\hline Application & $\begin{array}{l}\text { Creating the basis struc- } \\
\text { ture of an interactive } \\
\text { video. Application of } \\
\text { the basic notation ele- } \\
\text { ments like initialization } \\
\text { and branching. }\end{array}$ & 3 \\
\hline Comprehension & $\begin{array}{l}\text { Import and pre- } \\
\text { processing of video } \\
\text { material. Identification } \\
\text { and selection of raw } \\
\text { data and translation for } \\
\text { the use in a scene graph } \\
\text { model. }\end{array}$ & 4 \\
\hline Knowledge & $\begin{array}{l}\text { Creation of a new project } \\
\text { Knowledge about func- } \\
\text { tion buttons and settings. }\end{array}$ & 5 \\
\hline
\end{tabular}

Note: 5 indicates the worst learning quality level.

$T E$ is calculated with different timestamps generated within each participant's experimental session. After the introduction by an instructor, the experiment session starts (timestamp $A$ ). The next measurement point is taken when the last result is saved by the participant (timestamp $B$ ). A third and fourth timestamp is taken when the questionnaire is started $(C)$ and finally submitted $(D)$. Via this information, we calculate the $T E$ needed to complete the whole task $(C-A)$.

Additionally, we use the timestamps to delete invalid observations when the questionnaire is submitted without the final result being created $(C<B)$. This con- 
Table 3. Constructs of User Perceptions Examined with the Questionnaire.

\begin{tabular}{|c|c|c|}
\hline Construct & Description & Theoretical Foundation \\
\hline $\begin{array}{c}\text { Intrinsic } \\
\text { Motivation (IM) }\end{array}$ & $\begin{array}{c}\text { Extent of self-desired seek to use an interactive } \\
\text { video tutorial / PDF manual for learning } \\
\text { procedural knowledge. }\end{array}$ & $\begin{array}{l}\text { "Intrinsic motivation" of multi-motive } \\
\text { IS continuance model [30] }\end{array}$ \\
\hline $\begin{array}{l}\text { Hedonic Value } \\
\qquad(\mathrm{HV})\end{array}$ & $\begin{array}{l}\text { Extent of intention to use an interactive video } \\
\text { tutorial / PDF manual for performing a task. }\end{array}$ & $\begin{array}{l}\text { "Intention to use" of information } \\
\text { systems success model [31] }\end{array}$ \\
\hline $\begin{array}{l}\text { Technology } \\
\text { Affinity (TA) }\end{array}$ & $\begin{array}{l}\text { Open-mindedness of a person to use innovative } \\
\text { and unknown technologies. }\end{array}$ & $\begin{array}{l}\text { "Computer anxiety" of technology } \\
\text { acceptance model version } 3 \text { [32] }\end{array}$ \\
\hline $\begin{array}{l}\text { Tool Quality } \\
\text { (TQ) }\end{array}$ & $\begin{array}{l}\text { Ability to solve a task, based on personal and } \\
\text { external factors influencing the use of SIVA Suite. }\end{array}$ & $\begin{array}{c}\text { "Facilitating conditions" of unified } \\
\text { theory of acceptance and use of } \\
\text { technology [33] }\end{array}$ \\
\hline $\begin{array}{l}\text { Information } \\
\text { Quality (IQ) }\end{array}$ & $\begin{array}{l}\text { Degree of provided information is relevant to } \\
\text { solve the task. }\end{array}$ & $\begin{array}{l}\text { "Job relevance" of technology } \\
\text { acceptance model version } 3 \text { [32] }\end{array}$ \\
\hline Task Fit (TF) & $\begin{array}{l}\text { Fit of provided interactive video tutorial / PDF } \\
\text { manual for acquiring procedural knowledge to } \\
\text { solve a task. }\end{array}$ & $\begin{array}{l}\text { "Task technology fit" of technology to } \\
\text { performance chain [34] }\end{array}$ \\
\hline $\begin{array}{l}\text { Epistemic Value } \\
\qquad(\mathrm{EV})\end{array}$ & $\begin{array}{l}\text { Degree of acquiring relevant procedural } \\
\text { knowledge in the task domain. }\end{array}$ & Taxonomy of cognitive objectives [29] \\
\hline $\begin{array}{l}\text { Utilitarian Value } \\
\text { (UV) }\end{array}$ & $\begin{array}{l}\text { Extent of improvement regarding effectivity and } \\
\text { increase of satisfaction in performing a task. }\end{array}$ & $\begin{array}{l}\text { "Net benefits" of information systems } \\
\text { success model [31] }\end{array}$ \\
\hline
\end{tabular}

stellation of timestamps represents invalid observations which are not considered.

Besides $L Q$ and $T E$, we also examine the following eight constructs presented in table 3 with the questionnaire: Intrinsic motivation (IM) refers to the extent a person seeks to use a media format for learning. $\mathrm{He}$ donic value $(H V)$ represents the intention to use the interactive video tutorial / PDF manual and the satisfaction perceived when performing the task. Technology affinity (TA) is based on Venkatesh and Bala (2008) and describes how open-minded a person is towards innovative technologies [32]. To consider the ability of a person using the tool solving a task, we introduce the tool quality (TQ) which is influenced by personal and external factors. Information quality $(I Q)$ represents the quality of the provided information for solving a specific task. The task fit (TF) describes the capability of the media format to acquire procedural knowledge for solving a given task. The epistemic value $(E V)$ describes the scope of relevant knowledge which is acquired in the hypervideo domain. The perceived improvement of an individual when performing a task is considered as utilitarian value $(U V)$.

\subsection{Procedure}

Undergraduate and graduate students from the university are invited via a platform to take part in the experiment. All sessions are run by one instructor and the participants are randomly assigned to one of the two conditions. Every student is given a workstation with identical hardware (a notebook with a 17-inch screen, a wired mouse and headphones). The individuals' working areas are surrounded by sight protection to ensure that participants could only see their own workstation and working materials. At the beginning, the participants are introduced to solve the described task with the SIVA Suite software tool and use the provided interactive video tutorial or PDF manual as guidance. After finishing the task, the students are asked to complete a two-part questionnaire. While the first part focuses on demographics and prior experience, the second part asks about the usage and utilization of the interactive video tutorial / PDF manual and the students' self-assessment regarding the task (see constructs in table 3). The system stores the participant's results and $\log$ s the time effort needed to solve the task and fill out the questionnaire. To ensure that nobody finishes the task and the questionnaire under time pressure, the students are not allowed to leave until everybody is finished. As a reward for participation each student gets $10 €$ for participation.

\section{Analysis and Results}

In total 130 student participants are taking part in the experiment and are equally distributed across the two conditions regarding their demographics and previous experience (see table 4 on the next page). In the control group (PDF manual) we obtain 64 and in the treatment group (interactive video) 66 observations. 
Table 4. Demographics and Previous Experience.

\begin{tabular}{|c|c|c|c|c|c|}
\hline & \multicolumn{4}{|c|}{ Conditions } & \multirow{3}{*}{$\begin{array}{l}\text { Mann-Whitney- } \\
\text { U-Test (p-values) }\end{array}$} \\
\hline & \multirow{2}{*}{\multicolumn{2}{|c|}{$\begin{array}{l}\text { Interactive Video } \\
\text { mean } \quad s d\end{array}$}} & \multirow{2}{*}{\multicolumn{2}{|c|}{ PDF Manual }} & \\
\hline & & & & & \\
\hline Gender & \multicolumn{2}{|c|}{$62.12 \%$ female } & \multicolumn{2}{|c|}{$67.19 \%$ female } & 0.396 \\
\hline Age & 22.05 & $(2.249)$ & 21.91 & $(3.181)$ & 0.547 \\
\hline Semester & 3.79 & $(2.545)$ & 3.16 & (2.049) & 0.185 \\
\hline Use of Audio-Visual Media & 3.80 & (1.638) & 3.39 & (2.029) & 0.386 \\
\hline Use of Text-based Media & 3.56 & $(1.807)$ & 3.08 & (1.703) & 0.093 \\
\hline Use of Text and Graphic Based Media & 4.68 & $(1.279)$ & 4.66 & (1.224) & 0.753 \\
\hline Use of E-learning Systems & 2.47 & (1.657) & 2.25 & (1.574) & 0.440 \\
\hline Creation of Hyper-Text & 1.39 & $(1.528)$ & 1.34 & (1.576) & 0.786 \\
\hline Creation of Hypervideo & 0.83 & $(1.431)$ & 0.45 & $(1.083)$ & 0.111 \\
\hline
\end{tabular}

There are slightly more female respondents (64.6\%) and the average age is $21.98 \quad(\min =17, \max =37$, $\mathrm{sd}=2.738$ ). The students are in different majors: cultural studies $(n=31 ; 23.8 \%)$, business studies $(n=26 ; 20 \%)$, law studies $(n=17 ; 13.1 \%)$, European studies $(n=16$; $12.3 \%)$, teaching $(\mathrm{n}=11 ; 8.5 \%)$, political science $(\mathrm{n}=11$; $8.5 \%)$ and others $(n=18 ; 13.8 \%)$.

\subsection{Learning Quality and Time Effort}

To investigate differences in learning among the two conditions, a gamma distribution is assumed regarding the time effort (TE) and a negative-binominal distribution is underlying the learning quality $(L Q)$. Due to the distributions, we use the Mann-Whitney-U-Test as a non-parametric procedure and a T-test as a parametric approach to identify differences between the control condition and the treatment (see details in table 5). Regarding $T E$ (in minutes) we cannot see a significant difference between the PDF manual and interactive video tutorial, while $L Q$ is significantly better $(\mathrm{p}<0.05$, in both tests) when the interactive video tutorial is used.

Table 5. Differences Between Conditions.

\begin{tabular}{ccc}
\hline Measures & $\begin{array}{c}\text { Mann-Whitney-U } \\
\text { Test (p-values) }\end{array}$ & $\begin{array}{c}\text { T-Test } \\
(\mathbf{p} \text {-values) }\end{array}$ \\
\hline $\begin{array}{c}\text { Learning } \\
\text { Quality } \\
\text { Time Effort }\end{array}$ & $0.043^{* *}$ & $0.034 * *$ \\
\hline \multicolumn{3}{r}{ Note: $^{*} \mathrm{p}<0.1 ;{ }^{* *} \mathrm{p}<0.05 ;{ }^{* * *} \mathrm{p}<0.01$}
\end{tabular}

Although the students are approximately 3 minutes faster when using the interactive video tutorial (see table 6), we do not observe a significant effect of the treat- ment on $T E$. This shows that the $T E$ for learning procedural knowledge cannot be increased when using an interactive video tutorial instead of a PDF manual. Hence, there is no difference in the amount of time needed to grasp and process relevant information from the information sources.

Table 6. Descriptive Statistics of LQ and TE.

\begin{tabular}{|c|c|c|c|c|}
\hline \multirow[t]{2}{*}{ Measures } & \multicolumn{2}{|c|}{$\begin{array}{c}\text { PDF } \\
\text { Manual }\end{array}$} & \multicolumn{2}{|c|}{$\begin{array}{c}\text { Interactive } \\
\text { Video Tutorial }\end{array}$} \\
\hline & mean & $s d$ & mean & $s d$ \\
\hline $\begin{array}{l}\text { Learning } \\
\text { Quality }\end{array}$ & 1.41 & $(1.31)$ & 0.95 & (1.09) \\
\hline Time Effort & 61.23 & (11.77) & 58.15 & (11.12) \\
\hline
\end{tabular}

Note: LQ in learning quality levels and TE in minutes.

This result supports the assumption that the content provided in the treatment is not different from the content provided in the control condition which is in line with the model of working memory [7] and cognitive load theory [8].

In contrast, there is a difference in $L Q$ regarding the results of the task. Students who use the interactive video tutorial achieve significantly better results than students who are working with the PDF manual. This result is in line with prior empirical investigations studying the learning performance comparing videos and text (see studies in table 1). Additionally, we can see, that most of the participants are creating good to very good results (learning quality level 0 or 1 ) when using the interactive video tutorial, while the standard deviation of $L Q$ is larger when using the PDF manual (see table 6).

Hence, we can see a significant increase in the $L Q$ 
when using an interactive video instead of a PDF manual (see table 5). We apply a simple linear regression for a more detailed evaluation of results. We assume a gamma distribution in respect to the $T E$ and a negative binomial distribution for the $L Q$. The results are presented in table 7 and show that the treatment has a significant effect on the $L Q$. We observe a decrease in the learning quality level indicating a positive effect on the $L Q$ when using an interactive video tutorial instead of a PDF manual.

Table 7. Simple Linear Regression Results.

\begin{tabular}{lcc}
\hline & LQ & TE \\
& negative binomial & gamma \\
\hline Treatment & $-0.387^{* *}$ & -0.001 \\
& $(0.183)$ & $(0.001)$ \\
Constant & $0.728^{* * *}$ & $0.015^{* * *}$ \\
& $(0.277)$ & $(0.001)$ \\
\hline Observations & 130 & 130 \\
Log Likelihood & -189.033 & -503.515 \\
Akaike Inf. Crit. & 382.065 & $1,011.029$ \\
\hline \hline & \multicolumn{2}{c}{ Note: ${ }^{*} \mathrm{p}<0.1 ;{ }^{* *} \mathrm{p}<0.05 ;{ }^{* * *} \mathrm{p}<0.01$}
\end{tabular}

\subsection{User Perception}

Besides investigating learning quality $(L Q)$ and time effort (TE), we gather additional information about user perceptions in form of a questionnaire. All constructs are examined with at least four items and are highly reliable regarding their Cronbach's Alphas $(>=0.79)$ (see table 8).

Table 8. User Perception Constructs.

\begin{tabular}{lcc}
\hline Constructs & Items & $\begin{array}{c}\text { Cronbach's } \\
\text { Alpha }\end{array}$ \\
\hline Intrinsic Motivation (IM) & 7 & 0.83 \\
Hedonic Value (HV) & 4 & 0.86 \\
Technology Affinity (TA) & 4 & 0.83 \\
Tool Quality (TQ) & 8 & 0.91 \\
Information Quality (IQ) & 6 & 0.81 \\
Task Fit (TF) & 5 & 0.79 \\
Epistemic Value (EV) & 4 & 0.80 \\
Utilitarian Value (UV) & 5 & 0.89 \\
\hline \hline
\end{tabular}

In the questionnaire, the effect of the treatment on the measures is analyzed with a seven level Likert scale. For each measure we conduct an ordered logistic regression and observe the following effects when using an interactive video tutorial (see table 9 on the next page for detailed regression results):
There is no significant effect of the treatment on the intrinsic motivation $(I M)(\mathrm{p}<0.2)$ which supports the fact that $I M$ is assessed equally among all participants and is not affected by the learning media format. Moreover, we cannot ascertain a significant effect on the hedonic value $(H V)(\mathrm{p}<0.4)$. Hence, there is no differences in the intention to use an interactive video tutorial or a PDF manual to solve the given task as both treatment groups would use the provided media to solve a similar task again. This is due to the fact that both formats provide equal content in our experimental setting. We observe a weakly significant effect of the treatment on technology affinity $(T A)(\mathrm{p}<0.1)$, i.e. participants find it easier to handle the SIVA Suite. However, there is a significant affection of the perceived tool quality $(T Q)(\mathrm{p}<0.01)$. This represents that students using the PDF manual find it more difficult to operate the software tool. Although the content is the same in both formats, the self-assessed information quality $(I Q)$ is significantly better, when using the interactive video tutorial $(\mathrm{p}<0.01)$. Furthermore, the interactive video tutorial is better suited to acquire procedural knowledge to solve the given task which is represented by the task fit $(T F)(\mathrm{p}<0.001)$. This is also supported by the fact that the relevance of the acquired knowledge is significantly higher evaluated by students using the interactive video tutorial which can be seen in the epistemic value $(E V)$ $(\mathrm{p}<0.03)$. Additionally, we observe that the participants experience a significantly higher utilitarian value $(U V)$ when using the interactive video tutorial $(\mathrm{p}<0.002)$.

\section{Discussion}

Based on the results, we discuss practical implications for the use of interactive video tutorials in different domains. Additionally, we outline limitations of this study and describe aspects which should be investigated in future research.

\subsection{Implications}

From the presented results one can draw conclusions for different application contexts: i) organizational, ii) educational and iii) private.

i) When delivering digital or physical products organizations usually provide information about the use and functionality in regard to operation. If procedural knowledge should be imparted, our results recommend the use of interactive video tutorials. By using this media format, organizations can induce a higher customer satisfaction based on a better utilitarian value $(U V)$. In our scenario we observe that users evaluate the tools quality more positive when learning procedural 
Table 9. Regression Results for User Perception.

\begin{tabular}{|c|c|c|c|c|c|c|c|c|}
\hline & IM & TA & TQ & IQ & $\mathrm{TF}$ & UV & $\mathrm{EV}$ & $\mathrm{HV}$ \\
\hline Treatment & $\begin{array}{c}0.420 \\
(0.306)\end{array}$ & $\begin{array}{l}0.519^{*} \\
(0.309)\end{array}$ & $\begin{array}{c}0.880^{* * *} \\
(0.312)\end{array}$ & $\begin{array}{c}0.816^{* * *} \\
(0.312)\end{array}$ & $\begin{array}{c}1.248^{* * *} \\
(0.322)\end{array}$ & $\begin{array}{c}0.977^{* * *} \\
(0.315)\end{array}$ & $\begin{array}{l}0.721^{* *} \\
(0.310)\end{array}$ & $\begin{array}{c}0.284 \\
(0.307)\end{array}$ \\
\hline $\begin{array}{l}\text { Observ. } \\
\text { Log Likel. }\end{array}$ & $\begin{array}{c}130 \\
-422.532\end{array}$ & $\begin{array}{c}130 \\
-357.744\end{array}$ & $\begin{array}{c}130 \\
-417.187\end{array}$ & $\begin{array}{c}130 \\
-356.023\end{array}$ & $\begin{array}{c}130 \\
-359.655\end{array}$ & $\begin{array}{c}130 \\
-331.294\end{array}$ & $\begin{array}{c}130 \\
-328.588\end{array}$ & $\begin{array}{c}130 \\
-356.467\end{array}$ \\
\hline
\end{tabular}

knowledge. A higher user satisfaction when learning with interactive videos is complemented with better quality of the results. This may lead to a positive attitude towards the product, because a user might relate this satisfaction to the product. An increase in user satisfaction and product quality are not the only positive aspects. Additionally, the acquired knowledge is perceived as more relevant which is reflected in a higher epistemic value $(E V)$. Therefore, the product itself as well as related services are recognized more positively by customers when using interactive video tutorials instead of PDF manuals.

ii) As the learning quality $(L Q)$ can be improved with an interactive video tutorial, we recommend to use this format when teaching procedural knowledge in new domains. Due to a better information quality (IQ), this media type should be preferred when schooling approaches to solve specific tasks in information systems. Referring to the positive effects on learning in regard to quality (see $L Q$ ), motivation (see $I M$ ) and satisfaction (see $U V$ ), interactive videos can extend and improve existing learning scenarios.

iii) In a private context people often face the challenge in which way knowledge should be acquired if different alternatives are available. If one aims to learn how to solve a specific procedural task, our results recommend using interactive video tutorials instead of PDF manuals. Although there will not be any difference in time effort (TE), one can experience higher satisfaction (see $U V$ ) and quality (see $L Q$ ) which is reflected in a better outcome.

From a research point of view, we build our study on the dual-coding theory of Paivio (1971) [6] based on the working mind model from Baddeley and Hitch (1974) [7]. Our results support the theory as we observe a significant higher $L Q$ related to this media format combined with a significant effect of the treatment on the perceived $I Q$. Although the content provided is the same in both formats, the students using the interactive video tutorial generate significantly better outcomes. This leads back to the fact that a combination of visual and audio information can be processed in parallel which improves learning. With our results about $T E$ and $L Q$ in terms of learning performance we confirm results from prior work in two ways: On the one hand, we support studies that cannot find any effects of interactive videos when focusing on efficiency measures like time effort. On the other hand, we could confirm results from studies that found positive effects of interactive videos when considering quality measures. However, we argue that quality measures related to efficiency aspects (e.g. test results, exam achievement, etc.) might not fit as constructs evaluating learning performance.

\subsection{Limitations and Future Research}

In this study, we show that the use of interactive video tutorials affects learning when procedural knowledge is acquired. However, these results are subject to some limitations. First, we use a student sample in our laboratory experiment. Considering the average age of 22 , the participants are generally very familiar with the use of new digital technologies. We assume that the results might be different for a sample of older people due to the technology affinity and learning routines. Second, in the experiment the participants do not have any prior experience with the software tool and have to solve an unknown task in a very new domain. Although this creates a very stable experimental setting, results might be different when participants have used similar tools before. Therefore, our results are only valid in scenarios where procedural knowledge is acquired in a new domain. Third, in our treatment we change the visual information from text to pictures and add an audio content representing the text in the manual. One can argue that a third treatment would be necessary which represents an interactive video tutorial without verbal information 
to show differences between the three modes. But as a video without the audio information would be neither appropriate nor usable regarding the dual-coding theory, just the two relevant treatment formats have been considered.

Further research should investigate different scenarios and application domains considering these limitations. It would be interesting to see if there are any differences and effects when people have prior knowledge in the domain but try to solve an unknown or new task. This could lead to further implications about the relevance of media types for beginners compared to experienced users in different application domains. In addition, the time dimension should be investigated in more detail to see the sustainability of knowledge acquired with different media formats. In a future experiment, the same participants could be asked to solve the task again without using any additional information like the video tutorial or PDF manual. Comparing the new results with those from this experiment would give insights in how well knowledge is remembered over time.

\section{Conclusion}

Nowadays video tutorials are a widely-used instrument for learning how to solve certain tasks. Our research question referrs to the effects on the learning process when using interactive video tutorials compared to PDF manuals. Although prior work investigates effects of videos or animations compared to paper-based and digital text, it lacks in two points. i) Reference to reality: In most cases the alternative to a video tutorial is not a textual paper-based representation of information (e.g. a book), but a digital media type (e.g. a PDF document) provided via the internet. ii) Comparability: Hypertext documents are not comparable with videos because the hypertext structure provides additional features which a common video does not.

The study fills this research gap by investigating two comparable media formats which are used in reference to reality, i.e. interactive video tutorials and PDF manuals. Besides common video features the created interactive video provides additional functionalities like search options and a linked table of contents making it comparable to the PDF manual. Based on the dual-coding theory [6] we assume that learning procedural knowledge with an interactive video tutorial (multi-modal presentation of information) has a positive effect on the learning process compared to a PDF manual (single-modal presentation of information).

To answer the research question, we conduct a laboratory experiment with a $1 \times 2$ between-subjects design. 130 student participants are equally distributed across two conditions. The first condition represents the control group who use a PDF manual. The second condition is the treatment group who works with an interactive video. We see no significant difference in the time effort (see $T E$ ). However, we observe a positive effect of the results' quality (see $L Q$ ). Students learning with the interactive video tutorial produce a significantly better outcome than students working with the PDF manual. Furthermore, participants using the videos have a significantly more positive attitude and sentiment towards the software tool they use (see $T Q, T F, E V$ and $U V$ ). Although the actual content provided by both media formats does not differ, students evaluate the information within the video as more valuable than the one presented in the PDF manual (see $I Q$ ).

This research contributes to the IS field from two perspectives. First, it shows how a new technology could be utilized to motivate and enhance acquiring procedural knowledge regarding the use of IS. Interactive video tutorials could give support in delivering application-orientated knowledge and help in understanding the utilization of disruptive technologies like the current trends of cloud computing, machine learning and internet of things. Second, the results provide helpful insights and support the understanding why interactive video tutorials are better suited for application-orientated scenarios than hypertext documents.

Acknowledgment: We thank PAULA (Passau University Laboratory) for providing the laboratory resources. We thank our colleagues from the mirKUL project who developed the SIVA Suite.

\section{References}

[1] J. E. Gaskin, P. B. Lowry, and D. M. Hull, "Leveraging Multimedia to Advance Science by Disseminating a Greater Variety of Scholarly Contributions in More Accessible Formats," Journal of the Association for Information Systems, vol. 17, no. 6, pp. 413-434, 2016.

[2] G. Boyd and N. Kasraie, "Can MOOC Fires Bring Light to Shadow Education," International Journal of Learning and Development, vol. 3, no. 4, p. 87, 2013.

[3] D. Mogensen, "I Want to Do Moments: From Home to Beauty," tech. rep., Google, 2015.

[4] S. Schwan and R. Riempp, "The Cognitive Benefits of Interactive Videos: Learning to Tie Nautical Knots," Learning and Instruction, vol. 14, no. 3, pp. 293-305, 2004.

[5] S. Strecker, D. Kundisch, F. Lehner, J. M. Leimeister, and P. Schubert, "Higher Education and the Opportunities and Challenges of Educational Technology," Business \& Information Systems Engineering, vol. 60, no. 2, pp. 181-189, 2018.

[6] A. Paivio, Imagery and Verabla Processes. New York: Holt, Rinehart and Winston, 1971. 
[7] G. Alan D. Baddeley, "Working Memory,” 1974.

[8] J. Sweller, "Cognitive Load During Problem Solving: Effects on Learning," Cognit. Sci, vol. 285, no. 2, pp. 257-285, 1988.

[9] R. C. Clark and R. E. Mayer, E-learning and the Science of Instruction Proven Guidelines for Consumers and Designers of Multimedia Learning. John Wiley \& Sons, 4 ed., 2016.

[10] S. Tindall-Ford, P. Chandler, and J. Sweller, "When Two Sensory Modes Are Better Than One," Journal of Experimental Psychology: Applied, vol. 3, no. 4, pp. 257-287, 1997.

[11] H. K. Tabbers, R. L. Martens, and J. J. Van Merriënboer, "Multimedia Instructions and Cognitive Load Theory: Effects of modality and cueing," British Journal of Educational Psychology, vol. 74, no. 1, pp. 71-81, 2004.

[12] S. F. Harp and R. E. Mayer, "How Seductive Details Do Their Damage: A Theory of Cognitive Interest in Science Learning," Journal of Educational Psychology, vol. 90, no. 3, pp. 414-434, 1998.

[13] U. I. Magner, R. Schwonke, V. Aleven, O. Popescu, and A. Renkl, "Triggering Situational Interest by Decorative Illustrations Both Fosters and Hinders Learning in Computer-based Learning Environments," Learning and Instruction, vol. 29, pp. 141-152, 2014.

[14] R. E. Mayer, W. Bove, A. Bryman, R. Mars, and L. Tapangco, "When Less is More: Meaningful Learning from Visual and Verbal Summaries of Textbook Lessons," Journal of Educational Psychology, vol. 88, no. 1, pp. 64-73, 1996.

[15] B. Park, R. Moreno, T. Seufert, and R. Brünken, "Does Cognitive Load Moderate the Seductive Details Effect? A Multimedia Study," Computers in Human Behavior, vol. 27, no. 1, pp. 5-10, 2011.

[16] S. Y. Mousavi, R. Low, and J. Sweller, "Reducing Cognitive Load by Mixing Auditory and Visual Presentation Modes," Journal of Educational Psychology, vol. 87, no. 2, pp. 319-334, 1995.

[17] M. Florax and R. Ploetzner, "What Contributes to the Split-attention Effect? The Role of Text Segmentation, Picture Labelling, and Spatial Proximity," Learning and Instruction, vol. 20, no. 3, pp. 216-224, 2010.

[18] I. A. E. Spanjers, T. Van Gog, P. Wouters, and J. J. G. Van Merriënboer, "Explaining the Segmentation Effect in Learning from Animations: The Role of Pausing and Temporal Cueing," 2012.

[19] E. K. Stice, J. D. Stice, and C. Albrecht, "Study Choices by Introductory Accounting Students: Those Who Choose to Study by Reading Text Outperform Those Who Choose to Study by Watching Video Lectures," Working Paper, p. 38, 2015.

[20] M. Merkt, S. Weigand, A. Heier, and S. Schwan, "Learning with Videos vs. Learning with Print: The Role of Interactive Features," Learning and Instruction, vol. 21, no. 6, pp. 687-704, 2011.

[21] H. D. Brecht, "Learning from Online Video Lectures," Journal of Information Technology Education: Innovations in Practice, vol. 11, pp. 227-250, 2012.

[22] A. T. Wells and R. McCrory, "Hypermedia and Learning: Contrasting Interfaces to Hypermedia Systems," Computers in Human Behavior, vol. 27, no. 1, pp. 195-202, 2011.
[23] M. L. Defleur, L. Davenport, M. Cronin, and M. Defleur, "Audience Recall of News Stories Presented by Newspaper, Computer, Television and Radio," 1992.

[24] A. Furnham, E. Proctor, and B. Gunter, "Memory for Material Presented in the Media - the Superiority of Written Communication," Psychological Reports, vol. 63, pp. 935-938, dec 1988.

[25] J. H. W. van der Molen and T. H. A. van der Voort, "Children's Recall of the News: TV News Stories Compared with Three Print Versions," Etr\&D-Educational Technology Research and Development, vol. 46, no. 1, pp. 3952, 1998.

[26] H. J. Choi and M. Yang, "The Effect of Problem-based Video Instruction on Student Satisfaction, Empathy, and Learning Achievement in the Korean Teacher Education Context," Higher Education, vol. 62, no. 5, pp. 551-561, 2011.

[27] B. D. Beitzel and S. J. Derry, "When the Book Is Better than the Movie: How Contrasting Video Cases Influence Text Learning," Journal of Educational Computing Research, vol. 40, no. 3, pp. 337-355, 2009.

[28] G. Blickle, "Personality Traits, Learning Strategies, and Performance," European Journal of Personality, vol. 10, no. 5, pp. 337-352, 1996.

[29] B. Bloom, Taxonomy of Educational Objectives Book 1: Cognitive Domain. London: Longman, 2 ed., 1956.

[30] P. Lowry, J. Gaskin, and G. Moody, "Proposing the Multimotive Information Systems Continuance Model (MISC) to Better Explain End-User System Evaluations and Continuance Intentions," Journal of the Association for Information Systems, vol. 16, no. 7, pp. 515-579, 2015.

[31] W. H. Delone and E. R. Mclean, "The DeLone and McLean Model of Information Systems Success," Journal of Management Information Systems, vol. 19, no. 4, pp. 9-30, 2003.

[32] V. Venkatesh and H. Bala, "Technology Acceptance Model 3 and a Research Agenda on Interventions," Decision Sciences, vol. 2, no. 273-315, pp. 273-315, 39.

[33] M. G. Morris, M. Hall, G. B. Davis, F. D. Davis, and S. M. Walton, "User Acceptance of Information Technology: Toward a Unified View," MIS Quarterly, vol. 27, no. 3, pp. 425-478, 2003.

[34] D. L. Goodhue, R. L. Thompson, and B. D. L. Goodhue, "Task-Technology Fit and Individual Performance," MIS Quarterly, vol. 19, no. 2, pp. pp. 213-236, 1995. 